\title{
From Crisis to a New Routine
}

\author{
Pnina Hertz \\ Pediatric Psychologist Coordinator of Feeding Clinic-Hadassah Medical Center
}

*Corresponding author: Pnina Hertz, Pediatric Psychologist Coordinator of Feeding Clinic-Hadassah Medical Center; Email: PninaH2@hadassah.org.il

Received: May 01, 2020; Accepted: May 08, 2020; Published: May 08, 2020

\section{Opinion article}

Looking back, the days have passed quickly-fifty-five days in the shadow of a threatening and contagious virus, thirty-five days in quarantine, in accordance with the regulations and in case of infection when a person is asked to stop his/her routine - daily activities -- and change habits, opposition understandably rears its head. While the media repeatedly discusses exit strategies from the COVID-19crisis, the number of victim's increases and we have not yet totally succeeded in flattening the curve, I find that for me, it is best to stop, spend time in self-reckoning and in gaining insight. I am primarily motivated by self-accountability in my attempt to understand what is happening and how these scenarios impact my present and my future -- as much as is in my control. I hope this article is helpful to others, witnesses to and partners in the same ongoing global crisis. The content that I am presenting was formulated in the spirit of humanistic psychology, inspired by American psychologist and sociologist Abraham Maslow. Maslow presents a hierarchy of needs. In his approach, one can only move from a basic and broad level, to a higher, secondary, and more focused level, when the previous level has been achieved. The reality of life, as well as the theory's opponents, show that the stages may work parallel to the life axis.

According to Maslow's principles, we have to provide the primary, broad, schematic and conceptual needs, and maintain balance, before we can fulfill the high-level needs of self-actualization. When primary needs are sufficiently fulfilled and the person is not concerned with obtaining food (or money to purchase food), he is free to act in "growth mode" (in contrast with «deficiency mode»). That is to say, simply, if I were hungry and indigent, I probably would not be able to write this text, which I see as a work that supplies second or third order needs. The need for art, beauty and creativity - concepts underlying the principles of humanistic psychology -is not a fundamental need for homeostasis, but rather is driven by an upset equilibrium and creative tension. A person who is full will not continue to eat once he is full (unless he suffers from an eating disorder); however a person who travels the world and enjoys new vistas will continue to explore foreign and interesting places, and will experience tolerable mild tension. I will now focus on two interim levels on the pyramid of needs, level three and four. The third level focuses on belonging, identity and love based on friendship, family, and sexual intimacy. The fourth level focuses on respect and esteem, self-esteem and accomplishment. In my opinion, all of mankind strives to reach the top of the pyramid but attaining the fourth level is crucial for achieving mental health.
In order to experience respect and esteem, it is necessary to establish a sense of belonging to the family, the social community and the community of professional colleagues.

The ongoing viral crisis's profound harmful economic impact has been described and continues to be described in the media, centered on the Passover holiday, 2020. There are holiday expenses which are also felt without crises but heightened and additionally difficult when there is a temporary or ongoing loss of sources of income. The higher socioeconomic sectors of the population may not experience real threat nor feel the imbalance of physiological needs. They will not suffer starvation or uncomfortable environmental temperature, for example, but nonetheless will experience a professional threat, in light of the ongoing crisis that meets them in a mature developmental phase, in which professional definitions are a critical part of their self-identity. I have chosen to address this level of vulnerability, as well as offer ways of coping in the given situation. Our day-to-day life with its routine balances our physical and mental needs. The constancy and stability of our schedule make daily life and encourages food consumption at set times. Similarly, routine also targets the quantitative balance of household tasks and professional tasks. There are defined times for professional commitments, family, leisure and community. A breach in the routine may upset the balance and manifest in increased consumption of food, compulsive exercise, uncontrolled and addictive television viewing. After a break in the routine, and in striving for homeostasis, we may build a new routine, characterized by variety and optimal balance - if we act as rational adults who can accept a new reality.

Assuming our basic physiological needs are properly addressed, the new challenges during the corona virus outbreak are security in our physical requirements, job security, and a sense of family and community belonging. Respect and appreciation are expressed for example in our being essential workers. If we are absent from the workplace because we are not essential workers or if God forbid, ill with corona, and if our children are mature and independent, and manage distant learning diligently on their own, we may wonder as to our standing and in dispensability. We may feel non-essential. These feelings can be overwhelming in the face of boredom and inactivity, wasted time and an altered sense of time («I did nothing and it is already noon,» or "How often can one see Orange is the New Black?). This becomes even more cumber some and intense if we add self-flagellation, low self-esteem, and guilt feelings. Workers in the same organization may be jealous and frustrated by seemingly 
arbitrary decisions about their compulsory unpaid vacation or job layoff. They may feel angry, despairing, and helpless in the face of a system perceived as no less destructive than the virus. This may easily lead to feelings of loneliness and depression. We cannot significantly control the situation, but we can take responsibility for our mood and our moral obligation to ourselves and our surroundings to best utilize this unwelcome situation. Here we touch upon the individual's outlook and stance on life as to the question of «how» as well as his characteristic coping and troubleshooting patterns.

First, good to let the body and mind be in states of exaggeration and overdose and to let go of self-flagellation and self-blame, despite the tendency to do so. Best to skip the feelings of worthlessness and self-abnegation, and allow ourselves to dive into a new world, until we internalize the new, compulsory routine--perhaps we will even succeed to derive pleasure and satisfaction from it. The balance is likely to arrive at some stage if we do not get stuck in a pattern of stern self-judgment. Second, we have a golden opportunity to choose and decide what is worthwhile to practice during this time and what we wish to strengthen. In being responsible for our morale, we are free to choose strengthening self-care strategies and drop what weakens us. It will be better for us and our surroundings if we choose to be happy and write up a daily gratitude list, than if we list grudge and anger towards a friend who has disappointed us. Instead of being angry, we can make peace. We have an empty space of time that it is worth filling with value-oriented matters.

Third, I will relate to the opportunity, despite the virus and the quarantine, to partnership and togetherness in the given situation If we zoom in on our equality, regardless of social status or professional occupation, in the face of the virus, we can share together the gratitude of all those who remain alive. We can see the obligation of social distancing as a national obligation with an equal burden and moral responsibility-to consecrate life. We can choose to focus on the virus's lack of discrimination on the basis of gender, religion, or sector, and unite together against a common enemy. Fourth, we should remember and remind our surroundings that we are in an ongoing, but transient situation. The feelings accompanying the situation we have not chosen are also temporary and transient. Feelings are not facts and they, as we have said, are up to us. It will be easier for us to focus on the transience of life despite the overwhelming experiences of challenges and changes that accompany the plague. We can change our thinking if we imagine each day as the last day in quarantine, while simultaneously imagining our return tomorrow to our workplace from which we have physically distanced ourselves, as though it were the last day of the vacation, which necessitated an immediate return, without a gradual adjustment.

Fifth, the coping strategies in the given crisis encourage us as productive and creative human beings. The given days invite action and creativity, originating in human curiosity and the use of our unique skills (cooking, acting, writing). Spontaneous creativity in the spirit of the time aims to cope and solve problems created in an unexpected crisis, fill the paramount need for a pyramid of needs and relate to the individual's aspirations to express and realize himself/herself. The routine accompanied by cumulative life experience teaches us how to respond to our diverse needs, from our basic physiological needs to our unique human needs of self-actualization. A crisis may upset the balance; however that balance can be restored if we accept the situation without resisting and without self-blame, and if we commit to strengthening our constructive qualities and emotions, utilize the experience of our shared fate and remember that the COVID-19 crisis is transient and will pass. Spontaneous creativity, positive, spirited, flexible action, and our aspiration to adapt and adjust, can turn a crisis into a new routine, along with the new challenges. We will know how to address these challenges and the price they exact in the years to come, based on surveys, case studies and future research.

\section{Citation:}

Pnina Hertz (2020) From Crisis to a New Routine. Infect Dis Ther Volume 1(1): 1-2. 